\title{
Social media and citizen vigilance
}

Social media technologies (such as Facebook, Twitter, Google, YouTube, Snapchat and Instagram) have brought about radical changes in how the media systems of liberal democracies operate. The platform providers have become powerful actors in the operation of the media system, and in how it connects to political processes. At the same time, these companies claim political neutrality, because most of their content is created by their millions of users - perhaps creating far greater citizen vigilance over government and politicians. Ros Taylor and the Democratic Audit team examine how far the UK's social media system operates to support or damage democratic politics. Does it help to ensure a full and effective representation of citizens' political views and interests?

\section{How should the social media system operate in a liberal democracy?}

Social media should enhance the pluralism and diversity of the overall media system, lowering the costs for citizens in securing political information, commentary and evidence, and improving their opportunities to understand how democracy works.

$\downarrow$ Social media should be easily accessible for ordinary citizens, encouraging them to become politically involved by taking individual actions to express their views in responsible ways, and enabling them to take collective actions to promote a shared viewpoint.

$\downarrow$ The overall media system should operate as transparently as possible, so that truthful/factual content predominates, it quickly drives out misinformation, and 'fake news', 'passing off' and other lapses are minimised and rapidly counteracted.

The growth of social media should contribute to greater political equality by reweighting communication towards members of the public and non-government organisations, reducing the communication and organisational advantages of corporate actors, professional lobbyists or 'industrialised' content promoters.

$\downarrow$ By providing more direct, less 'mediated' communications with large publics, social media should enhance the capacity of politicians and parties to create and maintain direct links with citizens, enhancing their understanding of public opinion and responsiveness to it. 
Social media should unambiguously enhance citizen vigilance over state policies and public choices, increasing the 'granularity' of public scrutiny, speeding up the recognition of policy problems or scandals, and reaching the widest relevant audiences for critiques and commentary of government actions.

Platform providers argue that they do not generate the content posted on millions of Twitter sites or Facebook pages, but only provide an online facility that allows citizens, NGOs and enterprises to build their own content. However, these large companies also reap important network and oligopoly effects that increase their discretionary power, and their platforms have become increasingly salient factors in democratic politics. Therefore, regulation of their activities should be considered if they create monopolies or oligopolies, suppress rival competitors, unfairly undermine the viability of established media, fail to deal with extremism and hate speech, or damage the integrity of elections or other political participation processes.

$\downarrow$ Platform providers must take their legal responsibilities to 'do no harm' seriously, and respond quickly to mitigate new social problems enabled by social media that are identified by public opinion or elected politicians.

In assessing (and potentially regulating) social media effects, evidence-based knowledge of the actual, empirical behaviours of users and platform providers is key, rather than relying on a priori expectations.

The development of regulations and law around fast-changing 'new goods' like social media often lags behind social practice. Legislators and government need to be agile in responding to emergent problems created by social media, or to existing problems that are re-scaled or change character because of them. Where existing controls or actions to mitigate effects are already feasible in law, their implementation needs to be prioritised and taken seriously by police forces and regulators.

As with conventional media, citizens should be able to gain published corrections and other effective forms of redress (including appropriate damages) against reporting or commentary that is illegal, unfair, incorrect or invades personal and family privacy. Citizens are entitled to expect that platform companies will respect all laws applying to them in speedily taking down offensive content, and will not be able to exploit their power to deter investigations or prosecutions by the police or prosecutors.

Adverse by-product effects of social media use on established or paid-for journalism and media diversity needs to be taken into account. Social media companies argue that their activities are similar to 'disintermediation' ('cutting out the middle man') processes in other industries, allowing citizens more choice in how they gain information or services. Yet losses of advertising revenue to platform corporations that critically threaten the viability of existing media (like broadcasting and print/paidfor newspapers) may have net negative effects on the overall media system. 
Facebook and Google provide a cheap way for any political campaigner with money or large numbers of supporters to reach voters, often in a highly targeted way. Policy-makers need to consider how the new capabilities here affect the autonomy of citizens' voting decisions, and whether electoral law - which imposes obligations and restrictions on broadcasters - should be extended and adapted to encompass political advertising on social media platforms.

The growth of social media - and its wider consequences for the web - have been seen in rather different ways. On the one hand, easy-to-produce content and low-cost internet communication helps citizens in myriad ways to organise, campaign, form new political movements, influence policy-makers and hold the government accountable. Social media can also 'disintermediate' the conventional journalist-run and corporate-owned media. In 2008, Clay Shirky's Here Comes Everybody set out a vision in which self-publishing meant 'anyone can be a journalist'. Yascha Mounk points out that social media 'favours the outsider over the insider, and the forces of instability over the status quo'.

A populist discourse rationalising such changes argues that the mainstream media ('MSM') has stifled debate on issues that matter to 'ordinary' citizens. This pattern was observable in the EU referendum campaign (when the Leave campaign derided 'expert' opinions and urged people to 'take back control') and in the United States (where Donald Trump sought to bypass most media outlets in favour of direct communication at rallies and on social media). Some left critics also share the sentiment. Citing the LSE's study of negative representations of Jeremy Corbyn in the British press, Kadira Pethiyagoda describes a 'chasm between the masses and the elites, represented by the out-of-touch MSM, [that] threatens not only democracy and justice, but also stability'.

On the other side of the debate, new social goods, especially those that disrupt the established ways in which powerful interests and social groups operate, often attract exaggerated predictions (or even 'folk panics') about their adverse implications for society. Social media inherently present a double aspect, because they are run by powerful platform provider corporations (Facebook/WhatsApp/Instagram, Twitter, Google/You Tube and Apple).

Many providers seek to 'wall-in' millions of users within their proprietary domains. At the same time, almost all the content they carry is generated by individuals, firms or NGOs using free speech rights to communicate about the issues that matter to them. So, while the platform providers might seem oligopolistic in the way that they carve up the social media market, and in the enormous corporate power they have acquired relative to other companies, especially conventional media corporations, they can still claim to be politically neutral and competing for customers - and hence standing outside conventional media regulation provisions. 


\section{Recent developments}

In the realm of news and current affairs, the growth of social media in the UK has shrunk the audience for free TV news bulletins. For the BBC, the change means UK viewers can watch and consume news on PCs or smartphones, often playing clips rather than full bulletins. The readerships of most paid-for/print daily and Sunday newspapers has also fallen, although some Sunday titles and the free Metro are exceptions. Newspaper publishers that want to reach users on social media must either rely on existing readers recommending their content, or pay to advertise - even as papers' digital advertising revenues fail to live up to publishers' hopes and are scooped up instead by Google or Facebook. In addition, Facebook has reduced the amount of news in its newsfeed and announced that 'trusted' publishers - to be determined by public poll - will be given prominence. Thus social media are widely seen by journalists and others as posing an existential challenge for legacy publishers. (See Chapter 3.3.)

For a growing proportion of people, particularly among the 18-34-year-old demographic, online news reports represent their chief source of news. While many people use apps to follow the news, a growing number rely on stories shared via Twitter, Snapchat and, in particular, Facebook.

Figure 2 also shows that people value the ability to directly monitor what their political representatives and candidates are doing, and social media offers an easy way to do so. Currently $18 \%$ of all UK citizens follow a politician. In the case of councillors or even MPs, social media commentary is often the first thing to draw politicians' attention to causes and public concerns that do not reach them via constituency surgeries, council meetings or emails. The ability for people to click and comment in their own terms instantly helps to indicate the breadth and depth of public feeling on a particular issue.

Figure 1: Most used social media platforms for news consumption by people in the UK, 2018

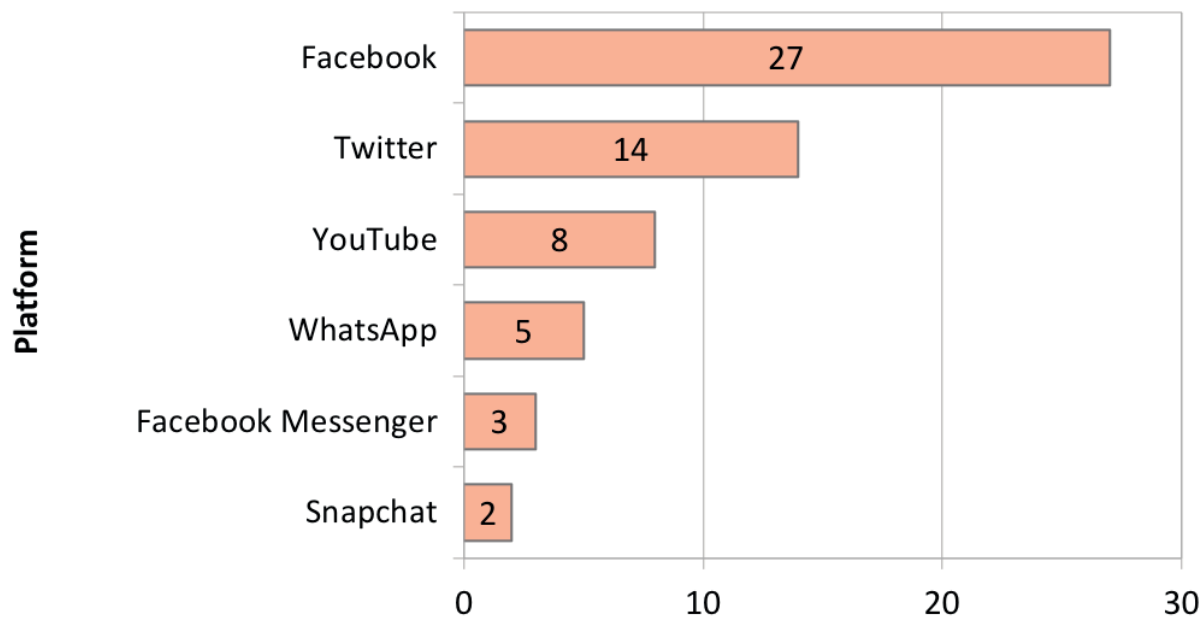

$\%$ of social media users getting news from different platforms

Source: Reuters Institute Digital News Report 2018 
Figure 2: Why people in six countries (including the UK) follow politicians on social media

I prefer to hear directly from a politician or political party than have their views filtered by others

I like a particular politician or political party

These feeds provide me with more detailed information than I can get via the news media

I don't think the news media report the views of politicians or political parties fairly

The mainstream news media tend to ignore the politician or party I follow

I want to show others who I support politically

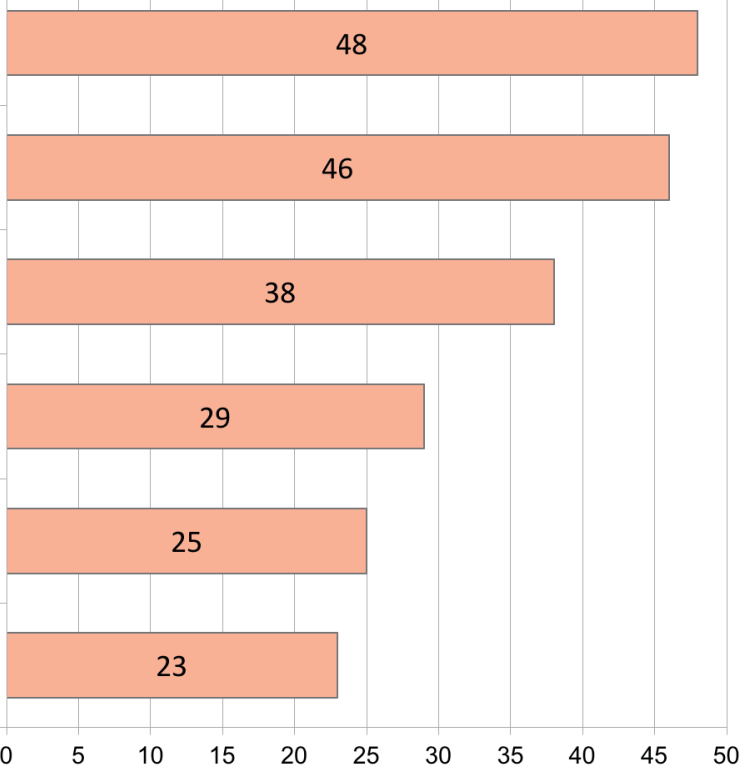

$\%$ of respondents following a political party on social media agreeing with the statement

Source: Reuters Institute Digital News Report 2017

Notes: Question was: 'You say you follow a politician or political party via social media, what are some of the reasons for this? Base: All who follow a politician or political party on social media, USA, UK, Germany, Spain, Ireland, and Australia. $n=2671$.

\section{Strengths, Weaknesses, Opportunities, Threats (SWOT) analysis}

\section{Current strengths}

Voters can follow their elected

representatives on social media, and candidates who are competing against them. By replying and commenting, people have low-cost opportunities to contact and influence them at a national or local level.

\section{Current weaknesses}

Platform providers give people the ability to customise the news they receive on social media. Most people use this facility as they use conventional media, paying most attention to viewpoints and sources with which they already agree. On tailored social media responding closely to citizen preferences, this behaviour can create a 'filter bubble' in which opposing or even unaligned voices go unheard. Only 4\% of social media users follow politicians from both the political left and right. Some politicians - not just in the US - use Twitter as a channel for angry and often inaccurate polemic, and corrections are rare and often go unnoticed. 


\section{Current strengths}

Even citizens unaffiliated with an organisation, can quickly disseminate their message to a very wide audience via social media and have some chance of evoking wider agreement from like-minded people a dynamic that drives retweeting, Facebook 'likes' and even now officially recognised online petitions to the UK government. The popularity of social media among young people provides a helpful means of encouraging them to get on the electoral roll, after the relative success of the online National Voter Registration Drives.

Digital-only publication and dissemination via social media have lowered the start-up costs for many alternative media outlets, broadening the range of professionally produced news and commentary available to citizens. Snapchat Discover has enabled mainstream publications like Le Monde and CNN to reach the 18-24 year-old audience more easily ( $10 \%$ reach in the UK) as legacy broadcast and printed press consumption declines.

Social media apps are nominally free to set up and use. Quite sophisticated media (like blogs, video streams and photo sites) are now also very cheap to run, and need no special training. Hence the growth of social media expands the foundations for a pluralistic and diverse media system.

\section{Current weaknesses}

Most 'retweeters' and 'likers' are not professional journalists writing for factchecked publications, but ordinary citizens with lower levels of information. So critics argue that inaccurate and misleading information ('fake news') can spread more quickly. For example, after the Grenfell Tower disaster online reports spread quickly that the government had issued a D-Notice restricting media reporting on the issue, which (of course) it had not.

Digital-only publishing by highly committed or partisan publishers has also enabled them to flood online platform systems with multiple biased or untrue messages in ways that are completely non-transparent. The ongoing US inquiries into the Trump administration's links with Russia have revealed the ability of foreign powers to use 'fake news' disseminated on social media to sway the political process, and allegations of similar influence in the 2016 Brexit referendum and 2017 election have been made. (See Chapter 2.4.)

There is evidence that online abuse and harassment, particularly of women, children, ethnic minorities, and socially unpopular groups, can be more extensive in social media than in society outside. Moving online increases the audiences for abuse, lets it occur in real time and more often, escalating faster, and often involving extreme language.

Online 'hate speech' is illegal in the UK but police and prosecutors have been slow to engage. Some cases of legal redress for defamation on Twitter have been successful, but this is a very costly process to accomplish. Many people complain that platform providers have been too slow to take down offensive, harassing or illegal content. So a lack of online 'civility', and harassment of vulnerable people, remain a serious problem. 


\section{Future opportunities}

The EU's new General Data Protection

Regulation (GDPR) began operating in late May 2018. It imposes more stringent requirements on social media companies operating in the EU (including the UK still) to better explain privacy rules to users and to get their active consent to their information being collected via cookies. Users can also more easily get redress if their information is leaked inappropriately or their privacy compromised.

The scandal around Cambridge Analytica's political operations (see Chapter 2.4) prompted major investigations of how millions of Facebook users' data leaked to them without users' authorisation. These developments triggered the questioning of Mark Zuckerberg by the US Congress and European Parliament.

\section{Future threats}

The platform providers (especially Facebook) launched big damage-limitation exercises in mid-2018, using the GDPR to claim advances in users' control. However, most users have no choice but to accept the complex 'terms of service' that companies enforce, or else lose the functionality, services and networks that the major platforms provide.

The European Commission (EC) has the population scale and legal resources to move vigorously against misuse of monopoly power by Microsoft (after it bundled its Explorer browser and stifled competition) and later by Google (over unfairly advantaging its own search engine hits). In mid-2017 the EC fined Google $€ 2.4 b n$ and a further $€ 4$.3bn for antitrust practices in 2018 , a substantial disincentive to monopolistic practices.

However, after Britain leaves the EU, it is unclear whether any UK government would have the motivation, legal resources or scale to act as vigorously. Even if stronger rulings were made, the UK is a much smaller and less salient market for these firms than the EU as a whole. In spring 2018 Zuckerberg declined a request to appear before a House of Commons select committee, going instead to the European Parliament.

The growth of fact-checking tools and websites, including automated fact-checking, enables rapid rebuttal of falsehoods especially if platform provider firms assist in the process. This ability improves with time.
The media landscape risks atomisation as citizens turn to news sources that are specialised to their political view, interests or local area (but see below), with a corresponding decline in the political salience ('valence') of top media issues. 


\section{Future opportunities}

Social media enables rapid and unprecedented scrutiny of policy-making and politicians' pronouncements, with stakeholders' and experts' opinions freely available on Twitter. Some liveblogs have tried to curate them, but this body of knowledge and inputs remains diffuse. It can be linked to formal mechanisms, such as select committees of the House of Commons.

\section{Future threats}

Armed with huge cash reserves (often gained from setting up complex taxavoidance schemes), the giant platform corporations have diversified into social media conglomerates. Facebook (which owns Instagram and WhatsApp), Google (which owns YouTube) and to a lesser extent Twitter, now dominate social media platforms. These corporations' power to shape how democratic discourse happens online is considerable, and almost unregulated at nation state level.

Outside the UK and US, growth in some key social media (like Facebook) appears to be levelling off in favour of the more closed environment of messaging applications. This poses its own challenges, given the difficulty of monitoring activity in private channels.

\section{How social media users behave}

Many critics of social media claim that they change the behavioural dynamics of information markets in adverse ways. The ability to 'like' and 'follow' like-minded individuals on social media, together with Facebook's use of algorithms that present news and posts based on a user's existing preferences, has led to fears that people increasingly obtain their news from a self-reinforcing 'filter bubble' of similar opinion - concerns famously expressed by Cass Sunstein. Evidence for filter bubbles is mixed, with one study suggesting social media users are exposed to more viewpoints than they would otherwise be. People are more likely to read news their friends and family recommend. Increasingly, however, research suggests that the roots of political polarisation lie in wider societal changes rather than social media behaviour.

In the social media world, the key metric of successful content is its ability to generate retweets or Facebook 'likes'. Chasing the advertising revenue that a 'viral' piece or video can generate has led some media publishers to produce 'clickbait' - sensationalist headlines that tempt the readers to click through to that story in preference to others on the page. While a great deal of clickbait content is celebrity or lifestyle journalism, some of it relies on distorted and sensationalised news stories. Ofcom research on how news is consumed through social media suggests that users are less engaged and rarely remember the source of a story. 


\section{Fake news}

The term 'fake news' is inevitably subjective and contentious. In some instances it is difficult to draw a clear line between fabricated stories online and the hyper-partisan coverage of several British tabloids. Ulises Mejias argues that to insist on a clear distinction between 'real' and 'fake' news 'bypasses any kind of analysis of the economics that makes disinformation possible and indeed desirable' in Western democracies. One notable development in the UK has been the ability of far-right groups such as Britain First to disseminate their message on social media under the guise of entertainment - and one of their false tweets fostering anti-Islamic sentiment was retweeted by the US President, Donald Trump (with no later apology). Britain First was banned from Facebook in early 2018.

As with traditional media (see Chapter 3.3), increasingly globalised media ownership has opened up opportunities for powerful actors and state-funded operations to influence democratic debate abroad. Leaked US intelligence, which claims Russia used online fake news to influence voters in the 2016 election, suggest that the phenomenon is a growing threat to the legitimacy of elections in the West. In his analysis of electoral manipulation across the world, Ferran Martinez i Coma notes a move away from ballot-stuffing and towards media manipulation.

\section{Threats to female politicians and activists}

Misogyny on social media remains a problem, despite the introduction of stricter rules by Twitter. Social media harassment has been the subject of numerous other complaints by female politicians and activists, especially at the 2017 general election. A 2016 Demos study suggests that women users are just as responsible as men for originating misogynist threats. Police action against hatred and threats online seemed to take a long time to get started, but a man and a woman were given prison sentences in 2014 for posting threats on Twitter against the feminist campaigner Caroline Criado-Perez.

'Trolling' of women politicians or those from ethnic minorities clearly inhibits their freedom to develop and express opinions and debate on Twitter and other social media, and so represents a threat to democratic discourse online. Other forms of misuse of social media - such as the bullying of vulnerable school students by others - can easily have tragic consequences in terms of mental harm and even suicides. There have been repeated criticisms of platform providers (many of whose founders espoused socially libertarian ideas) for being reluctant to take down hate speech content and self-regulate their content effectively. The sheer volume of content posted on networks makes the task of policing hate speech difficult. In Germany, enforcing the NetzDG law - which makes platforms liable for certain forms of hate speech - has proved costly for Facebook. The social media companies tend to only help state authorities with clearly illegal material, such as encouraging terrorism or promoting suicides. While Facebook has significantly revised its content moderation rules, they are not always enforced. Critics argue that the major platform providers could enhance their automated checks (for example, by developing better 'artificial intelligence' systems), but have been dragging their feet so as not to lose the clicks (and ad revenues) that sensationalist 'fake news' attracts. 


\section{Hyper-local social media}

A more positive trend has been the development of hyper-local news, with half of sites run by people with some form of mainstream journalistic experience. Good quality sites may be able to partly offset the rapid decline of paid-for local newspapers across the UK by attracting crowdfunding and subscriptions. Micro-payments are another possible revenue stream, though they have developed much more slowly than anticipated. Hyperlocal news strengthens the voices of community groups and members of the public, whereas the traditional local press 'are very authority-oriented in their sourcing strategies'. But, Andy Williams explains, most outlets depend heavily on volunteers: 'Despite the impressive social and democratic value of hyper-local news content, community news in the UK is generally not a field rich in economic value'. So he concludes that for all their valuable efforts, unpaid and part-time news producers 'can only very partially plug growing local news deficits'. A Cardiff University initiative has sought to support hyper-local and community journalism by offering online training and funding advice, chiefly in Wales, which has a particular democratic deficit in coverage of regional/local news.

\section{Conclusions}

Social media clearly offers unprecedented opportunities for voters to debate and scrutinise public policy, albeit on terms heavily conditioned by the platform providers. As a tool for influencing and holding the political class accountable for their actions, it may ultimately prove as powerful as the press itself, which increasingly relies upon social media channels to reach younger people. Yet there is also a constant 'arms race' between citizens finding their online voices and the countervailing development of industrialised/professionalised social media campaigning by companies, large vested interests, political parties and some government actors. For good or ill - as the Trump presidency vividly demonstrates - social media allow politicians to communicate directly with citizens, enthusing the electorate and reinforcing their bond with supporters.

The blooming of multiple voices enables those who have traditionally been on the fringes of debate to make their voices heard, such as citizens with disabilities, However, it also opens a channel for extremists and news outlets with motives going far beyond conventional partisanship to embrace attempts to skew and undermine democratic debate itself. Because users choose whom they follow and can exclude unwanted or dissenting voices, critics argue that social media can foster and sustain conspiracy theories and fake news. And because social media make strongly held (sometimes abusive) opinions so visible, they risk stoking social polarisation and alienating other people from the 'normal' political processes. Political advertising on platforms, meanwhile, poses an urgent challenge for electoral law - one that the Electoral Commission has recently highlighted.

Are the current main platforms fit for purpose in liberal democratic societies, either in being transparent about their user-monitoring policies, or the extent to which they cooperate with governments for security purposes, or their ability to foster democratic deliberation and thoughtful social learning? Fears that the hegemony and ubiquity of these platforms could be nudging people towards extreme political behaviour have already 
triggered criticism of the social media model that 'moves fast and break things'. Some form of regulation looks increasingly likely - or at the very least policies designed to moderate platform power and safeguard elections.

Ros Taylor (@rosamundmtaylor) is Research Manager at the LSE Truth, Trust and Technology Commission and co-editor of LSE Brexit. She is a former Guardian journalist and has also worked for the BBC. 